\title{
Prevalence of Chlamydia trachomatis Infection Diagnosed by Polymerase Chain Reaction in Female Sex Workers in a Northern Mexican City
}

\author{
Luis Francisco Sánchez-Anguianoㄹ, Nadia Velázquez-Hernández ${ }^{1}$, Fernando Martín Guerra-Infante², \\ Marisela Aguilar-Durán ${ }^{1}$, Alma Rosa Pérez-Álamos, Sergio Estrada-Martínez ${ }^{1}$, \\ José Antonio Navarrete-Flores ${ }^{1}$, Ada Agustina Sandoval-Carrillo ${ }^{1}$, Elizabeth Irasema Antuna-Salcido ${ }^{1}$, \\ Jesús Hernández-Tinoco ${ }^{3}$ and Cosme Alvarado-Esquivel ${ }^{3 *}$ \\ Institute for Scientific Research “Dr. Roberto Rivera-Damm”, Juárez University of Durango State, \\ Avenida Universidad S/N, 34000 Durango, Mexico \\ 2Departamento de Infectología, Laboratorio de Virología del Instituto Nacional de Perinatología, Departamento de Microbiología \\ de la Escuela Nacional de Ciencias Biológicas, Instituto Politécnico Nacional, D.F México \\ ${ }^{3}$ Faculty of Medicine and Nutrition, Juárez University of Durango State, Avenida Universidad S/N, 34000 Durango, Mexico
}

Received: 30 December 2018; accepted: 21 January 2019

\begin{abstract}
Purpose: We aimed to determine the association between Chlamydia trachomatis infection and female sex work, and the association between sociodemographic, obstetric, and behavioral characteristics of female sex workers and C. trachomatis infection.

Methods: Through a case-control study design, we studied 201 female sex workers and 201 age-matched women without sex work in Durango City, Mexico. C. trachomatis DNA was detected in cervical swab samples using polymerase chain reaction.

Results: C. trachomatis DNA was detected in $32(15.9 \%)$ of the 201 cases and in $6(3.0 \%)$ of the 201 controls (odds ratio $[\mathrm{OR}]=6.15 ; 95 \%$ confidence interval $[\mathrm{CI}]: 2.5-15.0 ; P<0.001$ ). The frequency of infection with $C$. trachomatis in female sex workers did not vary $(P>0.05)$ regardless of the history of pregnancies, deliveries, cesarean sections, or miscarriages. Regression analysis of the behavioral characteristics showed that infection with $C$. trachomatis was associated only with consumption of alcohol $(\mathrm{OR}=2.39 ; 95 \% \mathrm{CI}: 1.0-5.71 ; P=0.04)$.

Conclusions: We conclude that $C$. trachomatis infection is associated with female sex work in Durango City, Mexico. This is the first age-matched case-control study on the prevalence of $C$. trachomatis infection in female sex workers in Mexico using detection of $C$. trachomatis DNA in cervical samples.
\end{abstract}

Keywords: Chlamydia trachomatis, prevalence, female sex workers, case-control study

\section{Introduction}

Chlamydia trachomatis (C. trachomatis) is a ubiquitous, obligate, intracellular Gram-negative bacterial pathogen [1]. Humans are the only natural host of $C$. trachomatis [2]. This bacterium remains a significant public health burden worldwide [3]. It is estimated that 100 million cases of $C$. trachomatis infection occur annually [4]. C. trachomatis is the pathogen that is most often transmitted by sexual contact [5]. The clinical spectrum of infection with $C$. trachomatis varies from asymptomatic to several acute or chronic, local, and systemic diseases such as trachoma, oculo-genital, and neonatal diseases [6-7]. Infections with $C$. trachomatis of the lower female genital tract are frequently asymptomatic, undiagnosed, and untreated [4]. Pelvic inflammatory disease attributed to ascending genital $C$. trachomatis infections can result in ectopic pregnancies and infertility in women [4-5]. In addition, a recent meta-analysis demonstrated that individuals infected with C. trachomatis have a higher risk of cervical cancer [8]. $C$. trachomatis causes inclusion conjunctivitis of the newborn,

*Author for correspondence: Biomedical Research Laboratory. Faculty of Medicine and Nutrition, Juárez University of Durango State, Avenida Universidad S/N, 34000 Durango, Dgo, Mexico; Tel: +52-618 8130527; Fax: +52-618 8130527; E-mail: alvaradocosme@yahoo.com. with the female birth canal being the reservoir [9]. In addition, infection with $C$. trachomatis causes pneumonia and sepsis [10]. In men, C. trachomatis causes urethritis and epididymitis [11].

Little is known about the epidemiology of C. trachomatis infection in Mexico. The prevalence of $C$. trachomatis in women in Mexico has been determined in several population groups; for instance, $4 \%$ prevalence was reported in women in Cuernavaca City [12], 3.3\% prevalence was found in women with leucorrhea in Mexico City [13], and 7.3\% prevalence was reported in women in rural and suburban Oaxaca State [14]. However, female sex workers have shown higher prevalence of $C$. trachomatis infection. Uribe-Salas et al. [15] reported $11.1 \%$ prevalence of $C$. trachomatis in female sex workers in Mexico City. Whereas in 3 northern Mexican states, prevalence between $12.4 \%$ and $16.6 \%$ were found in female sex workers [16-17]. In the present study, by using a different study design (case-control) and laboratory method (polymerase chain reaction [PCR]) compared to those used in previous studies in female sex workers in Mexico, we aimed to determine the following: (1) the association between $C$. trachomatis infection and female sex work and (2) the sociodemographic, obstetric, and behavioral characteristics of female sex workers associated with $C$. trachomatis infection.

This is an open-access article distributed under the terms of the Creative Commons Attribution-NonCommercial 4.0 International License (https://creativecommons.org/licenses/by-nc/4.0/), which permits unrestricted use, distribution, and reproduction in any medium for non-commercial purposes, provided the original author and source are credited, a link to the CC License is provided, and changes - if any - are indicated. 


\section{Materials and Methods}

Study Design and Women Studied. Through a casecontrol study design, we studied female sex workers (cases) and women with occupations other than sex work (controls) in Durango City from November 2014 to May 2016. Female sex workers were enrolled at the Sanitary Inspection Clinic of the Municipal Government in Durango City, Mexico. The inclusion criteria for enrollment of female sex workers were female sex workers (1) registered in the Sanitary Inspection Clinic, (2) worked in the sex industry for at least one year, and (3) aged $\geq 18$ years old. Control subjects were women without sex work. Controls were sexually active women and enrolled at the Clinic for Family Planning in the Institute for Scientific Research. This public clinic is in Durango City, Mexico, and is part of Juárez University of Durango State.

Sociodemographic, Obstetric, and Behavioral Characteristics of Cases. We recorded the sociodemographic, obstetric, and behavioral data of cases with the aid of a questionnaire. Data about age, residence, birthplace, education, socioeconomic status, history of pregnancies, cesarean sections, miscarriages, and deliveries from all sex workers were obtained. Behavioral factors included duration (years) in the sex industry, area of work (urban, suburban, or rural), sex work in Mexican states other than Durango or abroad, contact with semen during vaginal intercourse, condom use, practice of oral or anal sex, injuries at sex work, and consumption of alcohol, tobacco or drugs.

DNA Extraction and Amplification. Cervical swab samples were obtained from participants and stored in a home-made 2SP (sucrose-phosphate) medium at $-70{ }^{\circ} \mathrm{C}$ until analysis. DNA was extracted from cervical samples by proteinase $\mathrm{K}$ digestion and phenol-chloroform extraction. $C$. trachomatis DNA was detected by PCR using primers of the omp A gen of C. trachomatis [18]. These primers generate the amplification of a 129-base pair fragment. The amplification mixture contained $1.5 \mathrm{mM} \mathrm{MgCl} 2,0.3 \mu \mathrm{M}$ primers, 1 unit of Taq polymerase (Promega, Madison WI, EUA), $0.16 \mathrm{mM}$ dNTPs, $2 \mathrm{ng}$ DNA, and buffer in a $50-\mu \mathrm{L}$ reaction volume. This amplification mixture was denatured at $95{ }^{\circ} \mathrm{C}$ for $10 \mathrm{~min}$. Then, samples were amplified in 34 cycles. Each cycle consisted of the following: denaturation at $95{ }^{\circ} \mathrm{C}$ for $1 \mathrm{~min}$, annealing at $61{ }^{\circ} \mathrm{C}$ for $2 \mathrm{~min}$, and extension at $70{ }^{\circ} \mathrm{C}$ for $1 \mathrm{~min}$. Samples underwent a final extension at

Table 1. Sociodemographic characteristics of female sex workers and prevalence of $C$. trachomatis infection

\begin{tabular}{|c|c|c|c|c|}
\hline \multirow[b]{2}{*}{ Characteristic } & \multirow{2}{*}{$\frac{\text { Women tested }}{\text { No. }}$} & \multicolumn{2}{|c|}{$\begin{array}{l}\text { Prevalence of } \\
\text { C. trachomatis } \\
\quad \text { infection }\end{array}$} & \multirow[b]{2}{*}{$P$ value } \\
\hline & & No. & $\%$ & \\
\hline \multicolumn{5}{|c|}{ Age groups (years) } \\
\hline$\leq 20$ & 10 & 0 & 0.0 & \\
\hline $21-30$ & 82 & 14 & 17.1 & 0.56 \\
\hline $31-40$ & 64 & 11 & 17.2 & \\
\hline$\geq 41$ & 45 & 7 & 15.6 & \\
\hline \multicolumn{5}{|c|}{ Birth place } \\
\hline Durango State & 163 & 24 & 14.7 & \\
\hline Other Mexican state & 38 & 8 & 21.1 & 0.33 \\
\hline \multicolumn{5}{|c|}{ Residence place } \\
\hline Durango State & 200 & 32 & 16.0 & \\
\hline Other Mexican state & 1 & 0 & 0.0 & 1.00 \\
\hline \multicolumn{5}{|c|}{ Education (years) } \\
\hline No education & 4 & 0 & 0.0 & \\
\hline 1 to 6 & 58 & 11 & 19.0 & 0.38 \\
\hline $7-12$ & 129 & 21 & 16.3 & \\
\hline$>12$ & 10 & 0 & 0.0 & \\
\hline \multicolumn{5}{|c|}{ Socio-economic status } \\
\hline Low & 39 & 8 & 20.5 & \\
\hline Medium & 160 & 24 & 15.0 & 0.4 \\
\hline
\end{tabular}

$70{ }^{\circ} \mathrm{C}$ for $10 \mathrm{~min}$. Amplification products were analyzed by electrophoresis in $2 \%$ agarose gel and stained with $0.1 \%$ ethidium bromide.

Statistical Analysis. Data were analyzed with the software SPSS version 15.0 (SPSS Inc. Chicago, Illinois). We calculated the odds ratio (OR) with $95 \%$ confidence interval (CI) to assess the association between $C$. trachomatis infection and sex work occupation. In addition, the association between $C$. trachomatis infection and the sociodemographic, obstetric, and behavioral characteristics of the female sex work were analyzed by the Pearson's chi-squared test and the Fisher exact test (when values were 5 or less). Variables of sex workers with a $P$ value $\leq 0.20$ obtained by bivariate analysis were further analyzed by multivariate analysis. We calculated the ORs and $95 \%$ CIs by regression analysis with the Enter method. Statistical significance was set at $P$ value $<0.05$.

Ethics. The Ethics Committee of the Institute for Scientific Research of the Juarez University of Durango State, Mexico, approved this project. Participation in the study was voluntary. Written informed consent was obtained from all cases and controls before enrollment.

\section{Results}

Four hundred and two women were enrolled in this study. Half $(n=201)$ of them were cases (female sex workers), and 201 were controls (age-matched women). Mean ages in cases

Table 2. Correlation between behavioral characteristics of female sex workers and C. trachomatis infection

\begin{tabular}{|c|c|c|c|c|}
\hline \multirow[b]{2}{*}{ Characteristic } & \multirow{2}{*}{$\begin{array}{c}\begin{array}{c}\text { Women } \\
\text { tested }\end{array} \\
\text { No. }\end{array}$} & \multicolumn{2}{|c|}{$\begin{array}{l}\text { Prevalence of } \\
\text { C. trachomatis } \\
\text { infection }\end{array}$} & \multirow[b]{2}{*}{$P$ value } \\
\hline & & No. & $\%$ & \\
\hline \multicolumn{5}{|c|}{ Duration in the sex industry (years) } \\
\hline 1 to 5 & 20 & 1 & 5.0 & 0.14 \\
\hline 6 to 11 & 47 & 11 & 23.4 & \\
\hline$\geq 11$ & 134 & 20 & 14.9 & \\
\hline \multicolumn{5}{|c|}{ Area of work } \\
\hline Urban & 196 & 32 & 16.3 & 0.74 \\
\hline Suburban & 2 & 0 & 0.0 & \\
\hline Rural & 1 & 0 & 0.0 & \\
\hline \multicolumn{5}{|c|}{ Sex activity in Mexican states other than Durango } \\
\hline Yes & 58 & 9 & 15.5 & 1.0 \\
\hline No & 142 & 23 & 16.2 & \\
\hline \multicolumn{5}{|c|}{ Sex activity abroad } \\
\hline Yes & 3 & 1 & 33.3 & 0.4 \\
\hline No & 198 & 31 & 15.7 & \\
\hline \multicolumn{5}{|c|}{ Condom use } \\
\hline Yes & 115 & 19 & 16.5 & 0.77 \\
\hline No & 80 & 12 & 15.0 & \\
\hline \multicolumn{5}{|c|}{ Contact with semen during vaginal intercourse } \\
\hline Yes & 86 & 13 & 15.1 & 0.74 \\
\hline No & 113 & 19 & 16.8 & \\
\hline \multicolumn{5}{|c|}{ Practice of oral sex } \\
\hline Yes & 121 & 16 & 13.2 & 0.18 \\
\hline No & 79 & 16 & 20.3 & \\
\hline \multicolumn{5}{|c|}{ Practice of anal sex } \\
\hline Yes & 17 & 1 & 5.9 & 0.31 \\
\hline No & 182 & 31 & 17.0 & \\
\hline \multicolumn{5}{|c|}{ Injuries during sex activity } \\
\hline Yes & 12 & 2 & 16.7 & 1.0 \\
\hline No & 187 & 30 & 16.0 & \\
\hline \multicolumn{5}{|c|}{ Alcohol consumption } \\
\hline Yes & 36 & 10 & 27.8 & 0.03 \\
\hline No & 165 & 22 & 13.3 & \\
\hline \multicolumn{5}{|c|}{ Tobacco consumption } \\
\hline Yes & 41 & 5 & 12.2 & 0.63 \\
\hline No & 160 & 27 & 16.9 & \\
\hline \multicolumn{5}{|c|}{ Drug use } \\
\hline Yes & 13 & 3 & 23.1 & 0.43 \\
\hline No & 188 & 29 & 15.4 & \\
\hline
\end{tabular}


Table 3. Results of the regression analysis of selected behavioral characteristics of female sex workers and infection with $C$. trachomatis

\begin{tabular}{lccc}
\hline Characteristic & Odds ratio & $\begin{array}{c}95 \% \text { Confidence } \\
\text { interval }\end{array}$ & $P$ value \\
\hline Duration in the sex & 0.31 & $0.03-2.43$ & 0.26 \\
industry ( $\geq 5$ years) & 0.59 & $0.27-1.28$ & 0.59 \\
Practice of oral sex & 2.39 & $1.0-5.71$ & 0.04 \\
Alcohol consumption & &
\end{tabular}

and controls were $33.06 \pm 9.76$ (range: $18-67$ ) years old and $33.08 \pm 9.79$ (range: $17-67)$ years old, respectively $(P=$ 0.98). C. trachomatis DNA was detected in $32(15.9 \%)$ of the 201 cases and in $6(3.0 \%)$ of the 201 controls. The difference in the prevalence of $C$. trachomatis infection found in cases and controls was statistically significant $(\mathrm{OR}=6.15 ; 95 \% \mathrm{CI}$ : $2.5-15.0 ; P<0.001)$. Bivariate analysis of socioeconomic characteristics of female sex workers showed no association $(P>0.05)$ between $C$. trachomatis infection and age, birthplace, residence, educational level, or socioeconomic status (Table 1). The frequency of infection with $C$. trachomatis in female sex workers did not vary $(P>0.05)$ regardless of the history of pregnancies, deliveries, cesarean sections, or miscarriages. With respect to behavioral characteristics, the variables, namely, duration in the sex industry, practice of oral sex, and alcohol consumption, showed $P$ values $\leq 0.20$ by bivariate analysis (Table 2), whereas other behavioral characteristics including area of work, sex work in Mexican states other than Durango or abroad, contact with semen during vaginal intercourse, condom use, practice of anal sex, injuries at sex work, consumption of tobacco, or drugs showed $P$ values $>0.20$ by bivariate analysis. Regression analysis of the 3 behavioral characteristics with $P$ values $\leq 0.20$ obtained by bivariate analysis showed that the infection with $C$. trachomatis was associated only with consumption of alcohol $(\mathrm{OR}=2.39 ; 95 \% \mathrm{CI}$ : 1.0-5.71; $P=0.04$ ) (Table 3).

\section{Discussion}

The epidemiology of C. trachomatis infection in female sex workers in Mexico has been scantly studied. We therefore aimed to determine the association between $C$. trachomatis infection and the occupation of female sex worker in Durango City, Mexico. We found a significantly higher frequency of $C$. trachomatis DNA in cervical samples from female sex workers than in those from control women without sex work occupation. This finding indicates that $C$. trachomatis infection is associated with the occupation of female sex worker. This age- and gender-matched case-control study thus demonstrates that female sex workers in Durango City have an increased risk of $C$. trachomatis infection. Comparison of our results with those reported in studies of female sex workers in Mexico is limited and should be interpreted with care because differences in the study design and in laboratory methods among the studies exist. There are few reports on the prevalence of $C$. trachomatis in female sex workers in Mexico. In a study performed in 3 cities (Durango, Zacatecas, and Torreón) in the north of Mexico, prevalence values between 5.2\% and $16.2 \%$ of C. trachomatis infection were found [17]. However, in such study, a cross-sectional design and an enzyme immunoassay which detects $C$. trachomatis antigen in endocervix were used [17]. In the present study, we used a case-control study design, and diagnoses of $C$. trachomatis infection were based on $C$. trachomatis DNA detection using PCR. In a study of female commercial sex workers in Mexico City, researchers found a prevalence of $11.1 \%$ of C. trachomatis infection obtained by cultures of the bacterium in McCoy cells and identification with fluoresceinated monoclonal antibodies
[15]. In an additional study, the same research group found $14.4 \%$ prevalence of $C$. trachomatis infection in female sex workers at the Mexico-Guatemalan border by analyzing cervical swab samples using a nonradioactive nucleic acid hybridization assay [19]. In a further study, $25.0 \%$ of female commercial sex workers in Mexico City had anti-C. trachomatis IgG antibodies [20]. However, our results obtained by detection of $C$. trachomatis DNA cannot be compared with those of seroprevalence of $C$. trachomatis infection. We compared our results with those obtained in studies of female sex workers in other countries using PCR methodology. The prevalence $(15.9 \%)$ of $C$. trachomatis infection found in our study is higher than the $6.6 \%$ prevalence of $C$. trachomatis endocervical infection reported in female sex workers in Hungary using plasmid PCR [21]. In contrast, the prevalence found in our study is lower than a $28.5 \%$ prevalence of $C$. trachomatis cervical infection found in female sex workers in Dakar, Senegal, using PCR [22]. The association between C. trachomatis infection and female sex workers found in our study agrees with the same association found in a study in Bangladesh, where researchers found a significantly higher prevalence value of $C$. trachomatis infection in 40 female sex workers $(58 \%)$ than in 110 sexually active women $(27 \%)$ using immunochromatography test and/or plasmid PCR [23].

We found an association between $C$. trachomatis infection and alcohol consumption in female sex workers. In a search of this association in the biomedical literature, we did not find any report. It is possible that alcohol consumption in female sex workers might be linked to risky behavioral factors for $C$. trachomatis infection. Further research about this association should be conducted.

\section{Conclusions}

We conclude that $C$. trachomatis infection is associated with female sex work in Durango City, Mexico. This is the first age- and gender-matched case-control study on the prevalence of $C$. trachomatis infection in female sex workers in Mexico using detection of $C$. trachomatis DNA in cervical samples. The association between $C$. trachomatis and consumption of alcohol deserves further investigation.

\section{Funding Source}

This study was financially supported by Juarez University of Durango State, Mexico.

\section{Authors' Contributions}

LFSA and NVH conceived the study protocol, performed the data analysis, and wrote the manuscript. FMGI and JHT performed data analysis and wrote the manuscript. JANF obtained the samples and clinical data. MAD, ARPA, AASC, and EIAS performed laboratory tests and data analysis. SEM performed statistical analysis. CAE participated in the design of the protocol, performed data analysis and wrote the manuscript. All authors read and approved the final version of the manuscript.

\section{Conflict of Interest}

The authors declare that no conflict of interest exists.

\section{References}

1. Hooppaw AJ, Fisher DJ. A Coming of Age Story: Chlamydia in the post-genetic era. Infect Immun 2015;84:612-21. doi: 10.1128/IAI.01186-15.

2. Witkin SS, Minis E, Athanasiou A, Leizer J, Linhares IM. Chlamydia trachomatis: the persistent pathogen. Clin Vaccine Immunol. 2017;24:e020317. doi: 10.1128/CVI.00203-17. 
3. Nans A, Ford C, Hayward RD. Host-pathogen reorganisation during host cell entry by Chlamydia trachomatis. Microbes Infect. 2015;17:727-31. doi: 10.1016/j.micinf.2015.08.004.

4. Hafner LM. Pathogenesis of fallopian tube damage caused by Chlamydia trachomatis infections. Contraception. 2015;92:108-15. doi: 10.1016/j.contraception.2015.01.004

5. Stock I, Henrichfreise B. Infections with Chlamydia trachomatis. Med Monatsschr Pharm. 2012;35:209-22; quiz 223-4.

6. Budai I. Chlamydia trachomatis: milestones in clinical and microbiological diagnostics in the last hundred years: a review. Acta Microbiol Immunol Hung. 2007;54:5-22.

7. Karim S, Souho T, Benlemlih M, Bennani B. Cervical cancer induction enhancement potential of Chlamydia trachomatis: A systematic review. Curr Microbiol. 2018. doi: 10.1007/s00284-018-1439-7.

8. Zhu H, Shen Z, Luo H, Zhang W, Zhu X. Chlamydia trachomatis infection-associated risk of cervical cancer: A meta-analysis. Medicine (Baltimore). 2016;95:e3077 doi: 10.1097/MD.0000000000003077.

9. Darville T. Chlamydia trachomatis infections in neonates and young children. Semin Pediatr Infect Dis. 2005;16:235-44.

10. Lopez-Hurtado M, Guerra-Infante FM. Early Neonatal infection by Chlamydia trachomatis. J Infect Dis Ther. 2014;2:5. doi: 10.4172/23320877.1000158

11. Clad A, Krause W. Urogenital chlamydial infections in women and men. Hautarzt. 2007;58:13-7.

12. Echániz-Avilés G, Calderón-Jaimes E, Carnalla-Barajas N, SotoNoguerón A, Cruz-Valdez A, Gatica-Marquina R. Prevalence of cervicovaginal infections caused by Chlamydia trachomatis among female population of the city of Cuernavaca, Morelos. Salud Publica Mex. 1992;34:301-7.

13. Reyes-Maldonado E, Díaz-Fuente LA, Gonzàlez-Bonilla CV, EsquerMendivi M, Jiménez EZ, Deleón RI. Detection of Chlamydia trachomatis by immunofluorescence, papanicolaou and immunoperoxidase in women with leucorrhea. Rev Latinoam Microbiol. 1996;38:65-73.

14. Acosta-Cázares B, Ruiz-Maya L, Escobedo de la Peña J. Prevalence and risk factors for Chlamydia trachomatis infection in low-income rural and suburban populations of Mexico. Sex Transm Dis. 1996;23:283-8.
15. Uribe-Salas F, Hernández-Avila M, Conde-González CJ, JuárezFigueroa L, Allen B, Anaya-Ocampo R, et al. Low prevalences of HIV infection and sexually transmitted disease among female commercial sex workers in Mexico City. Am J Public Health. 1997;87:1012-5

16. Alvarado-Esquivel C, García-Villanueva A, Castruita-Limones DE, Cardosa-Nevárez FJ, Ruiz-Astorga R. Prevalence of Chlamydia trachomatis infection in registered prostitutes in the city of Durango, Mexico. Salud Publica Mex. 2000;42:43-7.

17. Esquivel CA, Briones Ezcarzaga ML, Castruita Limones DE, Lazalde Ramos BP, Salas EV, Gutierrez AA, et al. Prevalence of Chlamydia trachomatis infection in registered female sex workers in northern Mexico. Sex Transm Dis. 2003;30:195-8.

18. Dutilh B, Bébéar C, Rodriguez P, Vekris A, Bonnet J, Garret M Specific amplification of a DNA sequence common to all Chlamydia trachomatis serovars using the polymerase chain reaction. Res Microbiol 1989;140:7-16.

19. Uribe-Salas F, Conde-Glez CJ, Juárez-Figueroa L, HernándezCastellanos A. Sociodemographic dynamics and sexually transmitted infections in female sex workers at the Mexican-Guatemalan border. Sex Transm Dis. 2003;30:266-71

20. Cravioto Mdel C, Matamoros O, Villalobos-Zapata Y, Peña O, GarcíaLara E, Martínez M, Castelo J, Sifuentes-Osornio J. Prevalence of antiChlamydia trachomatis and anti-Neisseria gonorrhoeae antibodies in Mexican populations. Salud Publica Mex. 2003;45:S681-9.

21. Petrovay F, Balla E, Németh I, Gönczöl E. Genotyping of Chlamydia trachomatis from the endocervical specimens of high-risk women in Hungary. J Med Microbiol. 2009;58:760-4. doi: 10.1099/jmm.0.008607-0.

22. Sturm-Ramirez K, Brumblay H, Diop K, Guèye-Ndiaye A, Sankalé JL, Thior I, et al. Molecular epidemiology of genital Chlamydia trachomatis infection in high-risk women in Senegal, West Africa. J Clin Microbiol. 2000;38:138-45.

23. Hoque SM, Hossain MA, Paul SK, Mahmud MC, Ahmed S, Mahmud $\mathrm{NU}$, et al. Detection of Chlamydia trachomatis by immunological and genetic methods in female sex workers and the local female population of reproductive age in Mymensingh, Bangladesh. Jpn J Infect Dis. 2013;66:256-9. 